\title{
PSEUDOTUMOR INFLAMATÓRIO DO PULMÃO
}

\author{
INFLAMMATORY PSEUDOTUMOR OF THE LUNG
}

\author{
Raul Lopes Ruiz Júnior, ACBC-SP ${ }^{1}$ \\ Antonio José Maria Cataneo, TCBC-SP2
}

\section{INTRODUÇÃO}

Pseudotumor inflamatório do pulmão é considerado uma neoplasia benigna de origem desconhecida ${ }^{1-3}$. A nomenclatura é inconsistente ${ }^{1} \mathrm{e}$, tem sido chamado também de Granuloma de Células Plasmáticas, Histiocitoma Fibroso, Fibroxantoma, Hemangioma Esclerosante, Sarcoma de Células Fusiformes ou Plasmocitoma ${ }^{1,2,4,5}$. A histologia revela áreas de necrose circundadas por células inflamatórias crônicas com proliferação fibrovascular do estroma, infiltrado de linfócitos e células gigantes mononucleares ${ }^{3}$. A etiologia ainda não é bem conhecida ${ }^{1-3,5}$. Esse tipo de alteração pode ser produto de algumas infecções, fúngicas ou bacterianas e até mesmo inalação de agentes irritantes ${ }^{2,3,5}$. O estudo anatomopatológico intra-operatório por congelação apresenta dificuldade para diferenciação entre linfoma, sarcoma e fibrose mediastinal ${ }^{1,4,5}$.

\section{RELATO DO CASO}

Paciente, masculino, 10 anos, branco, chegou ao Pronto-socorro com queixa de cansaço e palidez há 15 dias. Apresentava antecedente de anemia e sopro cardíaco.

Ao exame físico apresentava-se em bom estado geral, descorado, acianótico, afebril, e eupnéico. Peso: 24,9 kg; altura:1,31m; FC: 90bpm; FR: 24mrm. Coração: Bulhas rítmicas, normofonéticas, sopro sistólico 2+/4+. Pulmões: murmúrio vesicular presente bilateralmente, ruídos adventícios ausentes.

Foram realizados os seguintes exames:

- Eletrocardiograma: resultado normal para a idade.

- Radiografia de tórax: presença de massa em terço superior do hemitórax direito medindo $4 \mathrm{~cm}$ no seu mai-

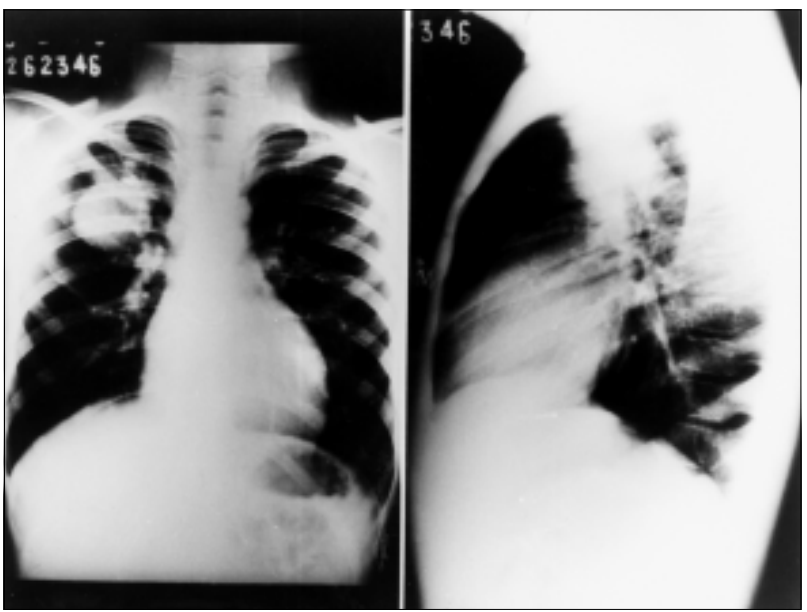

Figura 1 - Radiografias Simples do Tórax em P. A. e Perfil: à esquerda, massa em lobo superior direito medindo $4 \mathrm{~cm}$ no seu maior diâmetro; à direita, massa no segmento apical do Lobo Superior Direito.

or diâmetro, com limites precisos e sem aderências pleuropulmonares (Figura 1).

- Tomografia computadorizada do tórax: confirmando massa sólida em lobo superior direito (Figura 2).

Realizada a toracotomia exploradora, evidenciou-se nos lobos superior direito e médio, massa endurecida, com limites precisos, esbranquiçada e sem aderências pleuropulmonares, medindo $4 \mathrm{~cm}$ no seu maior diâmetro. O estudo anatomopatológico intraoperatório por congelação revelou processo inflamatório benigno. Foi, então, realizada bilobectomia superior e média, e o diagnóstico anatomopatológico definitivo foi pseudotumor inflamatório, predominando o tipo linfoplasmocítico.

1. Professor Assistente da Disciplina de Cirurgia Torácica da Faculdade de Medicina de Botucatu — UNESP

2. Professor Adjunto da Disciplina de Cirurgia Torácica da Faculdade de Medicina de Botucatu - UNESP

Recebido em 02/04/2001.

Aceito para publicação em 22/11/2001.

Trabalho realizado no Serviço de Cirurgia Torácica da Faculdade de Medicina de Botucatu — UNESP. 


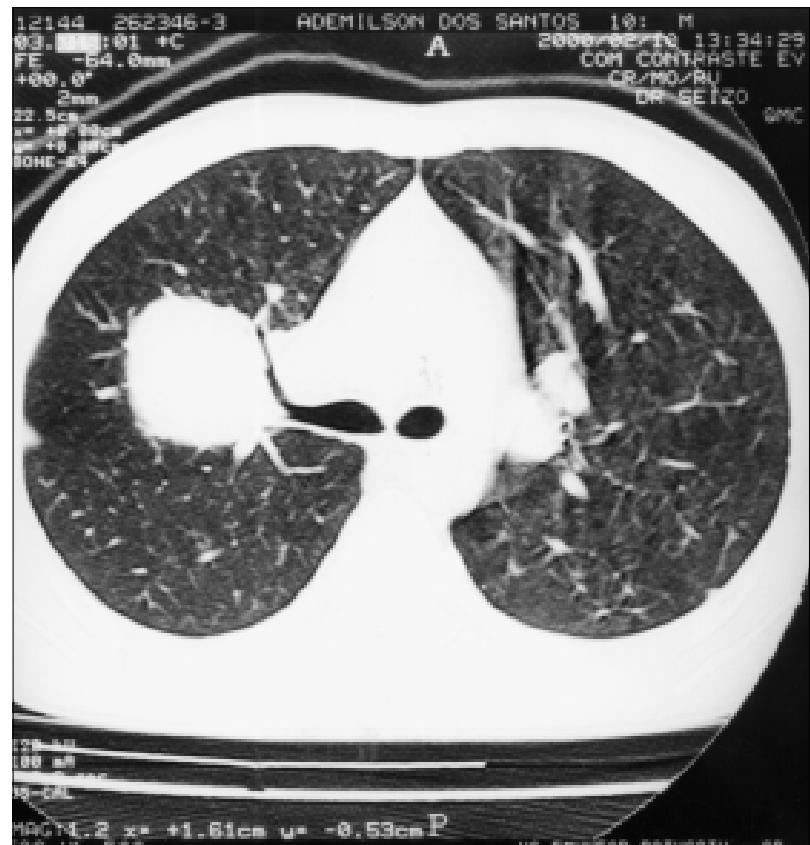

Figura 2 - Tomografia Computadorizada do Tórax: massa sólida no Lobo Superior Direito com contornos espiculados e com redução do calibre do brônquio.

\section{DISCUSSÃO}

O pseudotumor ocorre principalmente em jovens, sendo o tumor pulmonar primário mais freqüente em crianças abaixo de 16 anos de idade i, $^{1,4,5}$. Caracterizado por um processo inflamatório reacional aberrante ou exagerado à injúria tecidual, sem causa estabelecida, talvez relacionado a agentes infecciosos como vírus, fungos ou complexos antígeno-anticorpo ${ }^{1,4}$. O achado radiológico de nódulo solitário ou massa pulmonar periféricos raramente cavitados com ou sem envolvimento extraparenquimatoso, em radiografia de tórax de rotina, em pacientes jovens sem história clínica ou de doença relacionada sinaliza para uma ampla investigação $0^{2,4}$. Enfatizamos a ressecção completa do tumor tanto para diagnóstico como para proposta terapêuti$\mathrm{ca}^{1,2,4,5}$, pois pode simular neoplasia maligna do pulmão $\mathrm{o}^{2,4,5}$, apresentando invasão pleural, mediastinal, hilar, de via aérea ou de órgãos torácicos ${ }^{4,5}$, denotando um comportamento maligno. A recorrência pós-operatória pode ocorrer ${ }^{1,2,4,5}$.

O pseudotumor inflamatório tem variabilidade histológica e diversidade nas apresentações clínica e radiológica. A ressecção precoce e completa da lesão deve ser realizada para que haja confirmação do diagnóstico e exclusão do diagnóstico de malignidade, bem como para promover a cura e prevenir a recorrência, que deve ser tratada por re-operação.

\begin{abstract}
We report a case of a ten year old boy with an inflammatory pseudotumor in the right upper lobe. Surgical excision was undertaken. Inflammatory pseudotumors of the lung often occur in children. We recommend complete resection for diagnosis and cure. This tumor can mimic malignant neoplastic lesions and can recur after surgical treatment.
\end{abstract}

Key Words: Inflammatory pseudotumor; Lung; Recurrence; Malignancy.

\section{REFERÊNCIAS}

1. Cerfolio RJ, Allen MS, Nascimento AG et al. Inflammatory pseudotumors of the lung. Ann Thorac Surg, 1999, 67:933-936.

2. Santos LG, Barbosa JRA, Moraes WC. Pseudotumor inflamatório de pulmão: relato de um caso. Brasília Médica, 1997, 34(1/2):21-25.

3. Herman PG, Hillman B, Pinkus G et al. Unusual noninfectious granulomas of the lung. Radiology, 1976, 121:287-292.

4. Jubrail D, Charalambos Z, Niki A et al. Inflammatory pseudotumor: a controversial entity. Eur J Cardiothorac Surg, 1999, 16:670-673.
5. Alexious $\mathrm{C}$, Obuszko Z, Beggs D et al. Inflammatory pseudotumors of the lung. Ann Thorac Surg, 1998, 66:948950.

Endereço para correspondência:

Caixa Postal 501

18618-970 — Botucatu-SP

E-mail: ruizraul@fmb.unesp.br

E-mail: sira@laser.com.br 